\title{
Fertility Awareness and Biotechnological Application by Innovation Networks
}

\author{
Murcia Lora José María1*, Mejía Quiroga Jorge Enrique², M Ángeles Martínez Calvo Marian ${ }^{3}$ and Alberto Falces de \\ Andrés ${ }^{4}$ \\ ${ }^{1}$ Functional Reproductive Medicine and Biotechnology, Clinical Consulting G\&E, Logroño, Spain \\ ${ }^{2}$ Facultad de Ingeniería y Ciencias Básicas, Profesor Asociado, Universidad Central, Colombia \\ ${ }^{3}$ Universidad de La Rioja, España, Área de Ciencia de Materiales, Departamento de Ingeniería, Spain \\ ${ }^{4}$ Departamento de Ingenieríainfront, Universidad de la Rioja, Spain \\ Received: 阱 July 02, 2018; Published: 䟱July 12, 2018 \\ *Corresponding author: José María Murcia Lora, Functional Reproductive Medicine and Biotechnology, Clinical Consulting G\&E, Clinical \\ Consulting G\&E, 26002 Logroño (La Rioja) Spain, Tel: +34 941229 441, +34 619170 491; Email: humanreproductiongye@gmail.com
}

\section{Abstract}

The novelty and interest in the recognition of fertility related to the biophysical properties of cervical secretion is evaluated. Some basic physiological concepts and renowned schools that have contributed to these advances are cited. As a novelty, some of the referring devices related to the technological advancements in this field are related. Through a network study of patent citations and applying a network analysis algorithm, the clinical and biotechnological interest of studying the behavior of the biophysical properties of cervical secretion is checked.

Keywords: Fertile Window; Biotechnology; Fertility Awareness; Biomarkers; Ovulation; Menstrual Cycle; Cervical Secretion; Sterility; Subfertility; Infertility; patent citation networks

Abbreviations: IFFLP:International Federation for Family Life Promotion; EIFLE: European Institute for Family Life Education; AFLF: Africa Family Life Federation; WIPO: World Intellectual Patent Office

\section{Fertility Awareness and Biophysical Parameters of \\ Cervical Secretion}

The biophysical changes in the cervical secretion determine, and can influence the viscosity, which is directly proportional to the estrogenic impregnation, which varies from the initial follicular phase to the luteal phase, and is maximum in the periovulatory phase. Currently most studies define the period of greatest fertility from day -6 , prior to ovulation, until the first day after ovulation, and it is in this time interval when the change of days usually happens. Infertile, to the days of greatest fertility in the follicular phase of the menstrual cycle [1]. Currently it is known that the variability in the composition and production of cervical mucus is clearly regulated by the production of estradiol. At the preovulatory period, it becomes of the order of 600 to $700 \mathrm{mg} /$ day, and outside the fertile window about 40 or $60 \mathrm{mg}$. This quantifiable difference in the amount of estrogen clearly determines type $\mathrm{E}$ (estrogenic) secretion, which is abundant, and can be quantified in quantity, appearance; transparency, consistency and stretching. These physiological findings are widely documented in the literature in several studies that confirm the trophic effects mentioned both at the serum and local levels [2-8]. The changes that occur from the follicular phase to the end of the luteal phase will determine the variability of changes in the biophysical properties of cervical secretion. There are currently several entities that have devoted great efforts to improve the recognition of fertility within the fertile window. Among them are, for example, ovulation issues, cervical secretion or fertile window: International Federation for Family Life Promotion (IFFLP) (now Link Committee of Family Life Organizations), World Organization Ovulation Method of Billings, European Institute for Family Life Education (EIFLE), Africa Family Life Federation (AFLF) or with universities (Institute for International Studies in NFP Georgetown University IISNFP, NFP ForschungsprojektNatürlicheFamilienplanung an der Universität Düsseldorf, Rome Center for Study and Research on Natural Fertility ISI Regulatory, and Omaha Pope Paul VI Institute for the Study of Human Reproduction, among others. These schools describe the fundamental changes, which obey the physiological effect produced by the trigger effect produced on estrogen at the threshold of FSH. From the physiological premise of Brown[9], who comes to say that at FSH levels between 15 to 20 milli units/ $\mathrm{mL}$, there is an elevation of estradiol above baseline values, which in turn determines that the Follicular development responds to a 
certain threshold of FSH. This physiological effect determines the recruited follicle progresses evolutionarily to a dominant follicle in physiological situations of normality.

\section{Fertility Awareness and Analysis of Networks by Nodes of Innovation}

Through a citation of novel studies in this regard based on the application of the classic studies of the Billings evolutionary recognition pattern, up to the present date the following analysis can be reached as seen in Figure 1. Taking into account an algorithm developed to relate citation technology [10], network models [11] and the innovation approach of Burt [12], a network analysis was performed following indegree centrality according to Wasserman [13]. For the elaboration of this analysis, some of the citations related to the recognition of fertility have been taken, which are summarized in Table 1, Figure 1 and Figure 2 shows how the most cited patent is US 4151831 and around there are 3 other patents with a smaller number of citations. Likewise, another 5 subgroups of patents can be seen as shown in Figure 1. This set of patents is fragmented and are not related to each other, which are treated in different subgroups of topics related to the recognition of fertility.
By including in the analysis, two more patents related to the biophysical characteristics of the cervical secretion (patents in red in Figure 2), contributed by the search of the World Intellectual Patent Office (WIPO); Three different effects can be seen as seen in Figure 2. The first effect in terms of the patent US2011106465 provided as a novelty in the search, which links to the set of most cited patents. This effect occurs through one of the two routes originated in the patent US899882282. A route is from US20130054150A1, cited by US201100331720A1. And the other originated route is from US899882282 and links the patent US2011106465 provided by WIPO with the most cited patent US4151831A. The other effect is observed is the patent US2014313322, which is not articulated with the rest of the patents. And the third effect is highlighted by the patents enclosed in green Circles. These patents become intermediaries (bridges) between important groups of patents. The most obvious case is presented in the bridge established between patents US4151831A and US3434810A. And for our analysis it is of particular interest because the patent US4151831A is an intermediary between the patent found by WIPO; US2011106465 and the most cited patent of all US4151831A.

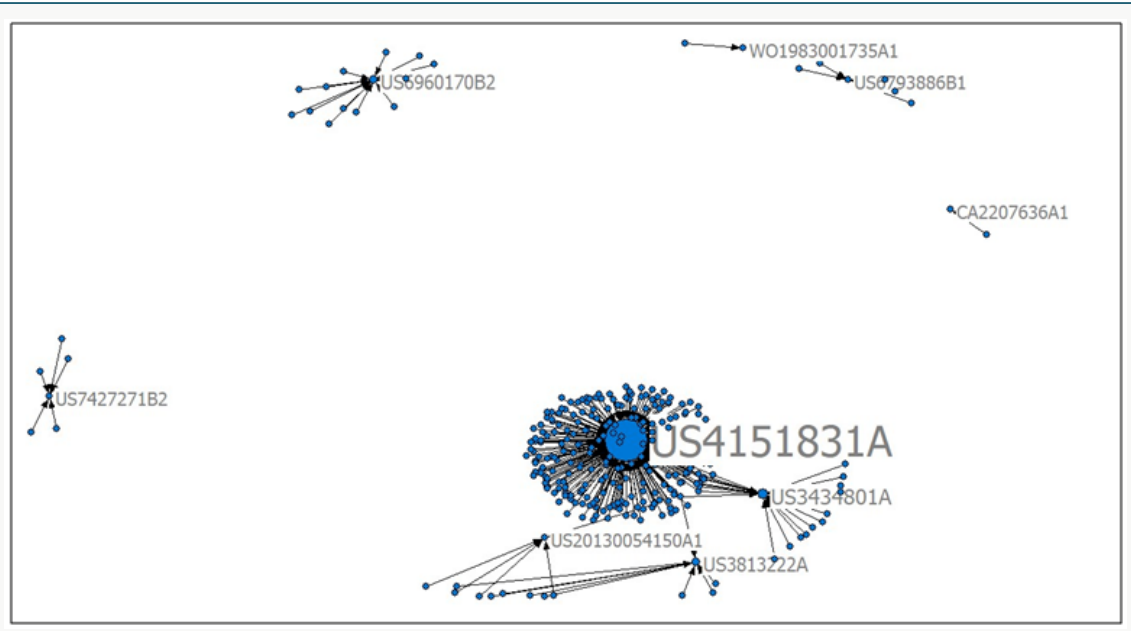

Figure 1: Patent citation network. Size of labels and nodes are proportional to Indegree Centrality [13]. Source: Own elaboration.

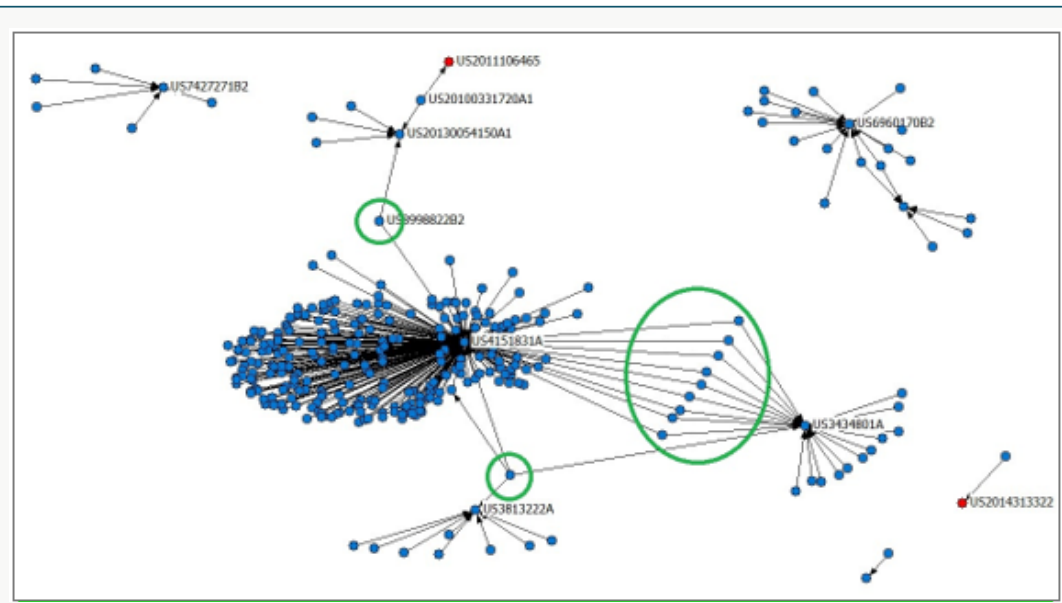

Figure 2: Patent citation network. The two patents found by WIPO (red nodes) are included. Patents circled in green are considered as bridges [13]. 
Table 1: Corresponding to Figure 1 and 2 Network Citations received. Including the patents found by WIPO.

\begin{tabular}{|c|c|c|}
\hline Patent number & Issue date & Title \\
\hline US3434801A & $1969-03-25$ & $\begin{array}{c}\text { Diagnostic test material for determination of ovulatory function and method for production } \\
\text { of said test material }\end{array}$ \\
\hline US3813222A & $1974-05-28$ & Method of determining ovulation time in urine and fertility in females \\
\hline US4151831A & $1979-05-01$ & Fertility indicator \\
\hline US6960170B2 & $2005-11-01$ & Image processing system for predicting ovulation \\
\hline US7427271B2 & $2008-09-23$ & Diagnosis of fertility status by folliculogenesis monitoring in the vagina \\
\hline US20100331720A1 & $2010-12-30$ & Device and method for determining a rheological property of mucus \\
\hline US20110106465A1 & $2011-05-05$ & System for tracking female fertility \\
\hline US20130054150A1 & $2013-02-28$ & Novel Ovulation Prediction Device \\
\hline US20140313322A1 & $2014-10-23$ & Portable preprogrammed thermometer for indicating fertility status \\
\hline US8998822B2 & $2015-04-07$ &
\end{tabular}

\section{Conclusion}

In summary, in the analysis applied to the review carried out, the contribution of this application demonstrates the structural interest of studying the biophysical properties of cervical secretion. That is, through the relationship of links between some of the subsets of patents shown here as a network, the subgroups of patents include some of the references close to the technique of analyzing the biophysical properties of cervical secretion. Strategies designed to increase the recognition of fertility through different clinical schools, network studies, and novelty analysis in the biotechnology area, justify and endorse the different working groups that integrate common research objectives in the same direction. This has been demonstrated and is applicable to the study of cervical secretion, not only from the point of clinical interest, but also biotechnological and its biosanitary repercussion.

\section{References}

1. Stanford JB (2015) Revisiting the fertile window. Fertil Steril 103(5): 1152-1153.

2. Adlercreutz H, Brown J, Collins W, Goebelsman U, Kellie A, et al. (1982) The measurement of urinary steroid glucuronides as indices of the fertile period in women. World Health Organization, Task Force on Methods for the Determination of the Fertile Period, special programme of research, development and research training in human reproduction. J Steroid Biochem 17(6): 695-702.

3. Fehring RJ, Schneider M (2008) Variability in the hormonally estimated fertile phase of the menstrual cycle. Fertil Steril 90(4): 1232-1235.
4. Billings EL, Billings JJ, Brown JB, Burger HG (1972) Symptoms and hormonal changes accomplanying ovulation. Lancet 299(7745): 282284.

5. Hilgers TW (2004.) The Medical \& Surgical Practice of NaPro TECHNOLOGY. (1 $1^{\text {st }}$ edn.), Published by: Pope Paul VI Institute Press 6901 Mercy Road Omaha, Nebraska 68106, USA.

6. Stanford JB, Parnell TA, Boyle PC (2008) Outcomes from treatment of infertility with Natural Procreative Technology in an Irish general practice. J Am Board Fam Med 21(5): 375-384.

7. Scarpa, Dunson DB, Colombo B (2006) Cervical mucus secretions on the day of intercourse: An accurate marker of highly fertile days. European Journal of Obstetrics \& Gynecology and Reproductive Biology 125(1): 72-78.

8. Hilgers TW, Prebil AM (1979) The ovulation method-vulvar observations as an index of fertility. Obstet Gynecol 53: 12-22.

9. Brown JB (1978) Pituitary control of ovarian function-concepts derived from gonadotropin therapy. Aust NZJ Obstet Gynaecol 18(1): 47-54.

10. Mejía,J (2015) Develando patrones de innovación en redes longitudinales de patentes por medio de leyes de potencia y entropía de información. Universidad Javeriana, Bogotá D.C. Colombia, Mayo. https://repository. javeriana.edu.co/handle/10554/16780.

11.V Blondel, C Daskalakis, D Gamarnik, A Ozdaglar (2012) Information and Decision in Social Networks. presented at the Interdisciplinary Workshop on Information and Decision in Social Networks, MIT.

12. Burt RS (2004) Structural holes and good ideas. American Journal of Sociology 110(2): 349-399.

13. Waserman S, Faust K (1994) Social network analysis: methods and applications. Cambridge; Cambridge University Press, New York, USA. 
(C) (i) This work is licensed under Creative

To Submit Your Article Click Here: Submit Article

DOI: $10.32474 /$ IGWHC.2018.02.000136
Interventions in Gynecology and Women's Healthcare

\section{IGWHC}

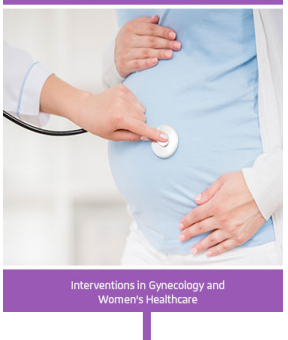

\section{Assets of Publishing with us}

- Global archiving of articles

- Immediate, unrestricted online access

- Rigorous Peer Review Process

- Authors Retain Copyrights

- Unique DOI for all articles 